\title{
Chemical Characterization of Silicon-Germanium Single Crystals - Initial Evaluation of the Extent of Heterogeneity
}

\author{
R. B. Marinenko*, J. T. Armstrong*, S. Turner*, E. B. Steel*, and F. A. Stevie** \\ *National Institute of Standards and Technology (NIST), MS 8371, Gaithersburg, MD 20899 \\ **Analytical Instrumentation Facility, Room 318, EGRC Box 7531,1010 Main Campus Drive \\ North Carolina State University, Raleigh, NC 27695-7531
}

Silicon germanium technology is having a profound impact on the wireless and computer industries due to the development of electronic components that are smaller, faster, less noisy and require less power than conventional silicon technology [1]. This trend will most likely continue since the fabrication cost of silicon germanium devices is nearly as inexpensive as for silicon and little retooling is required. Along with the rapid development of the SiGe technology has come the need to characterize the thin films used in the new devices. NIST is working with the semiconductor industry to use electron probe microanalysis (EPMA), Auger analysis, analytical electron microscopy (AEM), and secondary ion mass spectrometry (SIMS) to determine the composition, extent of heterogeneity, and thickness of industry-produced SiGe thin films on Si. These films will become available to other laboratories for characterization as part of an "Interactive Materials" reference program designed to share materials and analytical results among microanalysis laboratories.

Three SiGe wafers sliced from single crystal boules normal to the growth axis were obtained from a commercial source for use as reference standards. The extent of heterogeneity of these wafers was evaluated with EPMA. The nominal compositions of the three wafers were 14, 6.5 and 3.5 atomic \% $\mathrm{Ge}$ in Si. The dimensions of each wafer were different and are listed in Table 1. A survey of the heterogeneity of most of the surface of each wafer was needed before they could be cleaved into smaller specimens. For the purpose of processing the data, each specimen was divided into rectangular sectors, or samples (sizes in Table 1), excluding most of the extreme edges. Four or five different points were sampled in each sector and x-ray counts were acquired three times on the same point. Specimens were not carbon coated. Analysis conditions were $20 \mathrm{kV}, 60$ or $80 \mathrm{nA}$, and a

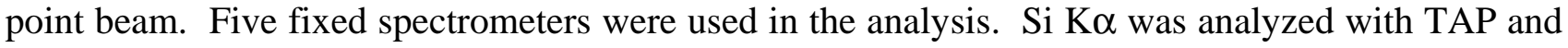
PET crystals (GP, gas flow P-10 detectors), GeK $\alpha$ with two LiF crystals (sealed Xe detectors), and $\mathrm{GeL} \alpha$ on TAP (GF). Count rates varied from as low as $2700 \mathrm{cts} / \mathrm{s}$ for $\mathrm{GeK} \alpha$ to as high as 225,000 for $\mathrm{SiK} \alpha$ on TAP for the $\mathrm{Si}(3.5) \mathrm{Ge}$ wafer. X-ray counts from the five fixed spectrometers (two for $\mathrm{Si}$ and three for $\mathrm{Ge}$ ) were acquired simultaneously for $20 \mathrm{~s}$ or $40 \mathrm{~s}$ and were later corrected for current drifts (usually less than 1\% relative). These data (not background corrected) were processed with a nested design analysis of variance procedure used previously at NIST [2,3]. Although this procedure may be modified slightly in the near future, it meets our present need to express the extent of heterogeneity for these wafers. In this procedure, a variance is calculated for the between points component, for the between specimen (or sector) component, and for the experimental uncertainty. These variances are calculated from the repeated readings taken from several randomly selected points within each sample (or sector). From the known concentration of the bulk wafer and an experimentally determined background (determined later for each x-ray line), an overall uncertainty due to the heterogeneity contribution can be calculated for a group of analyzed samples. An 
expanded uncertainty $(3 \sigma)$ was calculated for the data acquired from each wafer. The values obtained were less than $1 \%$ relative for the $\mathrm{Si}(14) \mathrm{Ge}$ and the $\mathrm{Si}(6.5) \mathrm{Ge}$ wafers. But for the $\mathrm{Si}(3.5) \mathrm{Ge}$ wafer this uncertainty was about $1 \%$ relative for $\mathrm{Si}$ and $3 \%$ relative for Ge. Results are listed in Table 1.

Plots of the X-ray count data versus acquisition sequence for each spectrometer and of GeK $\alpha$ or $\operatorname{L} \alpha$ counts versus $\mathrm{SiK} \alpha$ counts confirmed as well that the $\mathrm{Si}(14) \mathrm{Ge}$ and $\mathrm{Si}(6.5) \mathrm{Ge}$ specimens are less heterogeneous that the $\mathrm{Si}(3.5) \mathrm{Ge}$ specimen. This latter wafer demonstrated a definite correlation between the data from $\mathrm{Si}$ and Ge (as one increased the other decreased); in fact, plots suggested that there may be distinct phases present since groups of points fell in clusters. Such an effect was not seen for the other two wafers although the plotted data from $\mathrm{Si}(6.5) \mathrm{Ge}$ wafer showed a greater variability and spread in the data than was observed from the plots of the Si(14)Ge data. Straight-line traverses were taken normal to one another at two different locations on each wafer. Each traverse extended over 40 points that were $2 \mu \mathrm{m}$ or $5 \mu \mathrm{m}$ apart. These data also confirmed that the $\operatorname{Si}(3.5) \mathrm{Ge}$ wafer is more heterogeneous than the other two specimens and that the Ge and Si data is correlated.

The $\mathrm{Si}(14) \mathrm{Ge}$ and $\mathrm{Si}(6.5) \mathrm{Ge}$ specimens will be useful reference standards for analysis of the SiGe thin films. To evaluate the meaning of the extent of heterogeneity observed here, control wafers of pure $\mathrm{Ge}$ and $\mathrm{Si}$ wafers will be evaluated in a similar way. The $\mathrm{Si}(14) \mathrm{Ge}$ and $\mathrm{Si}(6.5) \mathrm{Ge}$ wafers will be cleaved into smaller samples. Some of these samples will be reevaluated for microheterogeneity with EPMA and analyzed for bulk composition by ICP-MS.

References

[1] S. Subbanna et. al., Future Fab Internatl., Issue 11, June 29, 2001

[2] ISO Guide 35, Certification of reference material - General and statistical principles, 2nd ed. Switzerland: Internat. Org. for Standardization (1989).

[3] J. Neter et al. Applied Linear Statistical Models, $4^{\text {th }}$ ed. Chicago Irwin/ McGraw-Hill (1996).

Table 1. Heterogeneity Evaluation of SiGe Wafers

\begin{tabular}{|c|c|c|c|c|c|c|c|}
\hline \multirow[b]{2}{*}{ Wafer } & \multirow{2}{*}{$\begin{array}{l}\text { Dimension } \\
\text { and } \\
\text { Sector Size } \\
(\mathrm{mm})\end{array}$} & \multirow{2}{*}{$\begin{array}{c}\text { No Sects, } \\
\text { No Pts, } \\
\text { No Rtps, } \\
\text { Time/pt }\end{array}$} & \multicolumn{5}{|c|}{$\begin{array}{l}\text { Expanded Uncertainty }(3 \times \sigma) \text { due to Specimen Heterogeneity } \\
\qquad \% \text { mass fraction }\end{array}$} \\
\hline & & & SiK TAP1 & GeK LiF2 & GeK LiF3 & GeL TAP4 & SiK PET5 \\
\hline $\mathrm{Si}(14) \mathrm{Ge}$ & $\begin{array}{l}20 \times 11.4 \\
5 \times 3.8\end{array}$ & $\begin{array}{l}12,4,3 \\
20 \mathrm{~s}\end{array}$ & 0.16 & 0.31 & 0.21 & 0.39 & 0.33 \\
\hline $\begin{array}{l}\mathrm{Si}(6.5) \mathrm{Ge} \\
\text { Bottom }\end{array}$ & $\begin{array}{l}15 \times 8.3 \\
7.5 \times 4.2\end{array}$ & $\begin{array}{c}4,4,3, \\
40 \mathrm{~s}\end{array}$ & 0.51 & 1.11 & 0.84 & 1.28 & 0.75 \\
\hline $\begin{array}{l}\mathrm{Si}(6.5) \mathrm{Ge} \\
\text { Top }\end{array}$ & $\begin{array}{l}17.2 \times 10.2 \\
7.9 \times 5.1\end{array}$ & $\begin{array}{c}4,4,3 \\
20 \mathrm{~s}\end{array}$ & 0.38 & 0.97 & 0.63 & 0.67 & 0.58 \\
\hline $\mathrm{Si}(3.5) \mathrm{Ge}$ & $35.4 \mathrm{dia}$ & $\begin{array}{c}4,5,3 \\
20 \mathrm{~s}\end{array}$ & 1.13 & 3.05 & 2.95 & 3.20 & 0.80 \\
\hline
\end{tabular}

